\title{
THE GROUND OF ALL NEGATIVE EXISTENTIAL TRUTHS
}

\author{
Julio De Rizzo \\ University of Hamburg \\ Germany \\ julioderizzo@gmail.com
}

SUMMARY: A natural proposal for the grounds of negative existential truths, such as that Vulcan does not exist, states that these truths are grounded in the totality truth affirming the existence of every existent thing together with the truth that they are all. In this paper I will put forward three objections to straightforward formulations of this idea, and argue that a change in the usual grammar of grounding claims, allowing for pluralities of sentences to express not only grounds, but also groundees, is effective in making the account immune to the objections raised.

KEY WORDS: metaphysical explanation, many-many grounding, existence, relevance, totality

RESUMEN: Una propuesta natural para el fundamento de existenciales negativos verdaderos, tales como Vulcano no existe, establece que estas verdades están fundamentadas en la verdad total que afirma la existencia de cada cosa existente junto con la verdad de que ésas son todas las cosas. En este artículo expondré tres objeciones a formulaciones directas de esta idea, y argumentaré que un cambio en la gramática usual de las afirmaciones de fundamentación, que permita que pluralidades de oraciones expresen no sólo fundamentos, pero también lo que está fundamentado, es efectivo al hacer la propuesta inmune a las objeciones presentadas.

PALABRAS CLAVE: explicación metafísica, fundamentación de muchos-a-muchos, existencia, relevancia, totalidad

\section{Introduction}

Negative existential truths, such as that Vulcan does not exist, or that Sherlock Holmes does not exist, are known for being the source of numerous puzzlements. In the context of the fashionable notions of grounding and metaphysical explanation, the question arises as to why these truths obtain, i.e. what are the grounds of these truths (if any). In this paper I will consider a group of answers to the latter question which employs totality truths, that is truths to the effect that this and that exist and that's all. I will put forward three objections to these accounts, and suggest that a change in the usual grammar of grounding claims, making room for pluralities to stand on the side of groundees, provides us with a way out of them. 
Here is a roadmap of what follows: after some preliminaries on grounding and negative existential truths in the next section, in section three I will proceed to the statement of the accounts and in the section thereafter to the objections against them. In the fifth section, I will then spell out and defend a fix of these accounts in terms of a grounding operator allowing for pluralities of truths on both sides. The final section concludes.

\section{Preliminaries}

Recent literature on metaphysics has seen a rapidly growing interest in the notion of grounding. ${ }^{1}$ I will take this notion to be expressible by the sentential operator "because", flanked by a plurality of sentences - possibly a single sentence - on its right side, expressing the ground, and a sentence on its left side, expressing the groundee. Thus "\{Quine\} exists because Quine exists"; "It is true that grass is green because grass is green", and "Napoleon's coat is blue because it is helvetia blue" are examples of usual grounding claims. In spite of the regimentation in terms of a sentential operator, for convenience, I will speak of truths standing as grounds and groundee.

A ground is said to metaphysically explain - fully or partiallyits groundee, where the relevant kind of explanation is of a distinctively metaphysical, non-causal sort. For simplicity, a truth is understood as a partial ground whenever it, on its own or together with other truths, constitutes a full ground. ${ }^{2}$ Thus the sun shines $\wedge$ grass is green because the sun shines, but the latter truth only partially helps bringing the former about: a full metaphysical explanation of the conjunction will have to cite that grass is green (or some further full ground of this truth) as well. Occasionally, I will insert "partially" before "because" to mark a partial grounding claim, which need not fully explain its corresponding groundee, and "full" as a subscript in "because" to indicate a full grounding explanation, when needed.

Importantly, as it is to be expected of explanations in general, the ground, full or partial, must be explanatorily relevant for bringing its groundee about. While the exact way of parsing out the notion of relevance here in play is still open for debate, it is a consensus that one would justifiably rule out purported examples of ground-

\footnotetext{
${ }^{1}$ For introductions and overviews, see Correia and Schnieder 2012a and Bliss and Trogdon 2016.

${ }^{2}$ Cf. Rosen 2010, p. 115.
} 
ing cases on the basis of failures of this relevance constraint. ${ }^{3}$ An account predicting, for example, that Plato exists partially because my cat exists would presumably fall short of this constraint. For our purposes, I will assume it to be intuitively clear what this notion of relevance amounts to, at least concerning the cases to be considered. I will come back to this point, which will play a role in due course.

I will adopt a fairly conservative stance on the logic of ground. Grounding, full and partial, is asymmetrical (hence irreflexive) and transitive. In saying, albeit not officially, that grounding obtains between truths, I also intend to suggest that "because" is factive in the straightforward sense that sentences flanking the operator in true grounding claims are true. Besides, I will assume full grounding obeys the following principle: ${ }^{4}$

Necessitarianism $\left(p\right.$ because $\left._{\text {full }} \Delta\right) \rightarrow \square(\bigwedge \Delta \rightarrow p)$

Even though almost every one of these assumptions has somehow been the target of discussions of its own, for reasons of space I will not enter into a proper defense of them. ${ }^{5}$

Call truths expressed by sentences of the form $\ulcorner a$ does not exist $\urcorner{ }^{6}$, for $a$ a name, e.g. those expressed by "Vulcan does not exist", "Sherlock Holmes does not exist", negative existential truths (negative existentials for short). ${ }^{7}$

To be sure, there are intricate issues on the semantics of nondenoting terms on the basis of which one might question the availability of genuine examples of this class. According to the so-called direct referential view of names, for instance, the semantic value of names is what they refer to. In addition, the truth of any sentence

${ }^{3}$ This plausibly plays a role in making grounding non-monotonic, that is, in it not being the case that, if $p$ because $\Delta$, then $p$ because $\Delta, q$, for an arbitrary $q$; and in making grounding contexts hyperintensional, that is, in it not being the case that substitution of intensionally equivalent truths (or pluralities thereof) in both sides of the grounding operator preserves truth in the resulting claim. See e.g. Fine 2012, pp. 38; 56. The relevance constraint plays a pivotal role in Dasgupta 2014, to which we will return in due course.

${ }^{4}$ Where " $\wedge \Delta$ " stands for the conjunction of every sentence in $\Delta$. The underlying modal logic is S5 throughout.

${ }^{5}$ For discussion and references in the literature on these assumptions, see Bliss and Trogdon 2016.

6 " $\ulcorner "$ and " ר" are devices of selective quotation à la Quine.

${ }^{7}$ Thus understood, the class of negative existential truths does not include those expressed, for example, by negations of existentially quantified sentences in general. This notwithstanding, some points of the discussion would plausibly carry over to this and further candidates usually falling under this rubric. 
in which names occur requires that they have a semantic value, and thus, on the view under consideration, a referent. But if a name such as "Vulcan" has a referent, then "Vulcan does not exist" turns out false after all, since the truth-condition of such a sentence seems to require that there isn't a thing which the name refers to. Thus, if we stick to this widespread view on the semantics of names, it seems either that "Vulcan does not exist" is not true, or, if it is, "Vulcan" as it occurs in such a sentence either semantically relates to something which does not conflict with the truth-condition in question (a concept, as per Bolzano and Frege, for instance; the existence predicate should be re-interpreted accordingly) or is not a direct referential name after all. On this latter option, it is plausibly a descriptive name, that is, a name with a descriptive content, i.e. whose referent is determined as whatever satisfies a certain description. (In the case of "Vulcan", the referent is stipulated as the planet in an orbit between Mercury and the Sun. Cf. Evans 1979.)

But even if every name in true negative existentials of the envisaged form we can grasp is descriptive in this sense, it is noteworthy that we can still ask, for every contingently existing object we do refer to, what reality would be like, had it not existed. ${ }^{8}$ Thus we can ask, of a possible scenario in which this table does not exist, what the ground of this possible truth would be.

Related to the mentioned worries concerning the direct referential view of names, one might reasonably cast doubt on the generality of any account of the grounds of negative existential truths thus circumscribed. This comes to light when we consider objects that do not exist, but could have. For the formulation of the respective negative existentials surely presupposes that we are able to refer to them. However, reference to nonexistents seems only to succeed in a reduced sphere of cases. Let us say, for example, that there are one handle and two blades, and that a knife can only have one handle and one blade assembled together. ${ }^{9}$ Suppose the handle is actually attached to the first blade B1. The knife which would result from the assembly of the same handle with B2 does not exist. But we surely can refer to it, as I just did. Let us stipulate that "Dolly dagger" names the knife which would have been made, were the handle attached to B2. This way, we are able to say meaningfully that "Dolly dagger does not exist", which is a true example of negative existential of the form

${ }^{8}$ Cf. Moore 1936, pp. 186-187.

${ }^{9}$ The example is borrowed with slight modifications from Williamson 1999, pp. 198-199. 
above. Nonetheless, it is plain that we should not expect to cover every true negative existential this way. For instance, Wittgenstein could have had plenty of daughters, who as a matter of fact do not exist, and reference to whom outstrips what we can express in languages coined on the basis of what we have at our disposal in actuality. Thus it seems that, for the most part, negative existentials of the form I intend to examine are simply beyond our reach.

There are two morals one could draw from these latter observations. On the one hand, one could take this limitation for granted, and restrict attention to those negative existentials we are able to meaningfully formulate. Arguably, given that plausibly many objects do not exist, but could have, the account inevitably would fall short of providing grounds for every true negative existential, taking into account every possible world. On the other hand, one might accept quantification over merely possible objects, and let the general account rest on this resource. Accordingly, an account of the grounds of negative existential truths in general will plausibly assume the form of a construction along the lines of "Every possible object is such that, if it does not exist, then it does not exist because ...", and would be of obvious interest, regardless of the fact that we might not have insight into the names occurring in every true negative existential which would instantiate the bound variable in each case. In the following, in order to preserve the intended generality, I will assume the accounts to be considered follow the latter route.

In citing the nonexistence of Sherlock Holmes as an example, I also intend to bracket particularities of fictional names, which might require a treatment of their own. Finally, concerning the predicate "exists", I should say that what follows is meant to be consistent in principle with different regimentations thereof, e.g. as a primitive, or as defined by means of the first-order existential quantifier and identity (as "is identical to something").

Now among enthusiasts of grounding, it is common place to attach the notion to questions of fundamentality. Accordingly, a truth with no grounds enjoys the elite status of being fundamental or - to speak more dramatically - of being a rock-bottom feature of reality. Throughout the paper I will suppose we have good reasons to deny this status to negative existential truths. This is a reasonable assumption: it is prima facie strange to let these truths stand on a par with truths of particle physics, say, or to let them earn their keep in the list of features standing at the bottom of reality's layered structure. ${ }^{10}$

${ }^{10}$ The non-fundamentality of negative existential truths might be further mo- 


\section{Totality Truths As Grounds for Negative Existential Truths}

Thus we see ourselves before the task of finding grounds for these truths. A natural proposal is this. Take the truth that Vulcan does not exist. Why does it obtain? Well, because I exist, you exist, this pen exists, ... and that's all! (Where the "..." covers all the existing things, which do not include Vulcan.)

Leaving issues around the formulation of the idea aside for a moment, let us note that this account is attractive for a number of reasons. Firstly, the ground pointed to cites only existent things. Intuitively, this gets the priorities right: what is the case in actuality should plausibly be explained solely by reference to what is the case with existent entities. Secondly, the grounding claim satisfies Necessitarianism. As a matter of fact, this is the main motivation for taking the that's all rider on board. For merely listing all the existential truths would not do: Vulcan could just be "added" to the picture, providing us with a possible scenario in which all the existential truths of this world still hold, while the groundee does not. Finally, this answer generalizes to every negative existential truth, enabling a greatly unified account of their grounds. ${ }^{11}$

The underlying idea might be expressed in at least two straightforward ways, differing as to whether they include the existential claims in the ground or not. ${ }^{12}$

1. Vulcan does not exist because (I exist, you exist, this pen exists, $\ldots, \forall x((x=m e) \vee(x=y o u) \vee(x=$ this pen $) \vee \ldots))$

2. Vulcan does not exist because $\forall x((x=m e) \vee(x=y o u) \vee(x=$ this pen $\vee \vee \ldots$ )

tivated by typical concerns surrounding the fundamentality of negative truths in general, or maybe some principle applying to fundamental truths, for instance that every truth must be accounted for by truths concerning only existent objects. For reasons of space, I will not discuss these motivations in detail.

${ }^{11}$ In the context of truth-making, Armstrong famously defends a closely related account. See Armstrong 1997. Merricks (2007, chapter 2) discusses the account in the same context. In the context of grounding, Loss (2017, p. 7) considers this view.

${ }^{12}$ Following what was said by way of stage setting, these formulations are supposed to be neutral as to how the existence predicate should be parsed. Though some changes in detail might be required by more informed views, the general idea would remain the same. 
(Where the "..." stands for further identities covering all existent entities. $)^{13}$ I will assume the idea is meant to apply with necessity to every negative existential truth, not only to this particular example. For further reference, let us label the general proposal underwriting 1. the abundant view and the one underwriting 2. the sparse view.

\section{Critique of the accounts}

Under closer inspection, both the abundant and the sparse views should be rejected. I turn now to the objections to these accounts.

4.1. First Objection. As mentioned above, a ground, partial or full, must be explanatorily relevant to its groundee. The abundant view goes against this relevance constraint. For, given the definition of partial ground, 1. has as consequence that Vulcan does not exist partially because I exist. And the same applies to every existent thing: even the existence of the smallest speck of dust in my window has a role to play in making it the case that Vulcan does not exist. This is surely an incredible result: it seems strange that any existent whatsoever is partially responsible for the nonexistence of the hypothetical planet. $^{14}$

The sparse view does not have this consequence. For, given the grounding rules for universal quantifications, " $\forall x((x=m e) \vee(x=$ you $) \vee(x=$ this pen $) \vee \ldots)$ " obtains partially because each of its instances obtains (Fine 2012, pp. 59ff.). And these instances -i.e., the disjunctions of identities resulting from each instantiation of the variable "x", e.g. " $(m e=m e) \vee(m e=$ you $) \vee($ me $=$ this pen $) \vee$ ..." - are grounded in their true disjuncts, which in turn are not partially grounded in the existences of the individuals referred to. Nonetheless, even if it escapes the irrelevance charge just raised, it is doubtful that letting the negative existential claim rest on identities pertaining to other objects is any way less objectionable. In other

${ }^{13}$ Instead of the formulation in terms of universal quantification, one could make use of a primitive totality operator, as in Leuenberger 2014. To keep the discussion concise, I will not address this formulation at length. Under plausible assumptions, the objections 1 and 3 discussed below might be taken to apply to this formulation as well. Apart from this, the formulations in the text could be enriched by including statements of non-identities between each existent object and Vulcan. The points of critique to be raised shortly would also carry over to the resulting accounts. Fine (2012) also argues for a regimentation of totality truths by means of an independent operator.

${ }^{14}$ Loss (2017) raises an analogous worry. Similar considerations play an important role in Dasgupta 2014, which we will consider in due course. 
words, if one holds that the existence of other individuals is irrelevant to the nonexistence of Vulcan, it is not clear why their identities should do any better on this score. ${ }^{15}$

4.2. Second Objection. Besides, the sparse view is susceptible to other worries. ${ }^{16}$ The first one is conditional on the following principle.

Internality: $(p$ because $\Delta) \rightarrow \square((\bigwedge \Delta \wedge p) \rightarrow(p$ because $\Delta))$

The thought behind this principle is that grounding is, in a sense, rigid: the ordering it induces is preserved across possible scenarios in which the truths ordered obtain. ${ }^{17}$

Now if Internality holds, the sparse view has an intriguing consequence. To simplify, consider a world $w_{1}$, the actual word, in which only $a_{1}, a_{2}$ and $a_{3}$ exist, suppose $a_{1}, a_{2}, a_{3}$ and $b$ are all the possibly existing individuals, and that each of them can exist with or without the other. Then the sparse view gives us the following claim:

$b$ does not exist because $\forall x\left(x=a_{1} \vee x=a_{2} \vee x=a_{3}\right)$

Possibly, $a_{3}$ and $b$ do not exist, while $a_{1}$ and $a_{2}$ do. In this world $w_{2}$,

$b$ does not exist because $\forall x\left(x=a_{1} \vee x=a_{2}\right)$

But by modal logic, $\square\left(\forall x\left(x=a_{1} \vee x=a_{2}\right) \rightarrow \forall x\left(x=a_{1} \vee x=a_{2}\right.\right.$ $\left.\left.\vee x=a_{3}\right)\right)$. Thus, in $w_{2}, " \forall x\left(x=a_{1} \vee x=a_{2} \vee x=a_{3}\right) "$ holds. By Internality,

$\mathrm{b}$ does not exist because $\forall x\left(x=a_{1} \vee x=a_{2} \vee x=a_{3}\right)$

${ }^{15}$ As an anonymous referee correctly notes, this objection might well turn on the regimentation of existence adopted. For the consequences drawn might be less objectionable if one regiments existence via the existential quantifier and identity, for instance, instead of a primitive first-order predicate. Though I grant the observation, it seems that the objection still raises an important concern, even for the view cited. For the derived partial grounding claims are surely unacceptable on an intuitive reading of ordinary existential claims, and it still needs to be argued why the regimentation should suffice in dispelling this uneasiness.

${ }^{16}$ This second objection does not prima facie apply to the abundant view or views which regiment totality truths by means of an operator.

${ }^{17}$ Litland (2015) discusses and rejects this principle as invalid in the logic of ground. Even if we accept Litland's counterexamples, some suitably restricted version of Internality might still generate the same problem. Admittedly, both the principle and the counterexamples deserve more space for discussion than I can provide here. Recently, Lovett (2019) defends Internality, conditioned on specific views of ground. 
is also true in $w_{2}$, even though $a_{3}$ does not exist in this world! In general, any expansion of the explanans with a further disjunct of the form $\ulcorner x=a\urcorner$, for $a$ a name of a possible existent distinct from $b$, will explain why $b$ does not exist in such a world (provided that possibly $a$ exists and $b$ does not). ${ }^{18}$ This should strike one as strange. The sole result that each negative existential has plenty of distinct grounds citing further nonexistents is anything but a desirable consequence. Besides, one might reasonably put to doubt the consequence that a nonexistent may be referred to when stating what makes it the case that other objects do not exist. For how could a nonexistent help make it the case that something does not exist in any way? Even if only mentioned in one of the disjuncts of the universal statement, the grounding claim referring to a nonexistent in the ground should be no less absurd than the claim, say, that a scarlet ball is red because it is scarlet or marine blue. In both cases, the added disjunct seems wholly alien to a proper explanation of its corresponding groundee. As a last point worthy of mention, note that this would multiply indefinitely the number of admissible grounds of a simple negative existential, provided the number of nonexistents is sufficiently large. Maybe some principle might be cooked up to tell apart "natural" from "unnatural" totalities as grounds for these truths, which would enable us to select genuine reasons why these negative existentials obtain. Be that as it may, even apart from the worries just raised, this potential cost should already be a clue that something goes amiss with the view we are considering.

4.3. Third Objection. The second worry one might raise against the sparse view also applies to the abundant view. It is based on the following distinction. In addition to the question of whether a sentence holds, one might reasonably ask for the way it holds, if it holds (or would hold, if it does not). Thus " $a$ is red" might hold by way of $a$ being scarlet, and it might also hold by way of $a$ being crimson. That there is a person might hold by way of me being a person, or by way of you being a person. In contrast, a conjunction might hold only by way of both of its conjuncts holding. ${ }^{19}$ Even if only

\footnotetext{
${ }^{18}$ If one takes for granted that Internality holds of necessity, then the argument can start with an alternative possible scenario and conclude with the result that in actuality the same situation arises. That is, the statement of a great number of grounds of negative existential truths holding in actuality cite nonexistent objects.

${ }^{19}$ Litland (2015) also writes of ways in a similar sense. Even though this loose talk of ways is naturally regarded as reflected in the grounds of such truths, we need not rely on a strict identification.
} 
stated in loose terms, it seems there is an important distinction to be recognized here: there are truths which can hold in more than one way; and there are truths which cannot. ${ }^{20}$

Now put in simple terms, the worry amounts to this: according to the accounts, there are many distinct ways in which a negative existential truth might obtain, one for each possible totality truth not 'including' the nonexistent in question. But nothing in the content of negative existential truths seems to support this high 'disjunctivity'. A disjunction, for instance, has built-in the source of the variety of ways in which it might hold, a characteristic arguably shared by determinables and usual existential quantifications. One could perhaps strengthen the point by saying that it is part of the meaning of disjunction, determinable predicates, and the existential quantifier that the possible truths expressed through sentences built from them might hold in principle in virtue of multiple circumstances. In contrast, negative existentials are not suggestive, in themselves, of any plurality of ways for them to be the case. Indeed, I suspect that any inclination pointing otherwise is explainable by a thoughtless acquiescence in the idea behind the accounts we are considering beforehand..$^{21}$

To be sure, maybe, relative to some objects, one can make good sense of their corresponding negative existentials holding in a variety of ways. Thus that the set $\{$ Quine, Lewis\} does not exist could hold by way of Quine not existing, or by way of Lewis not existing, or both. Or say that a state-of-affairs is a mereological compound, having its parts necessarily when it exists. Take, for example, the state-ofaffairs of Lewis having a long beard. The state could not have existed without any of its parts - Lewis, the property of having a long beard, for instance - existing. Again, this gives us distinct ways in which it might be said that the state could not exist. However, it should be plain that this does not extend to every negative existential truth. In particular, it is far from clear that the same line of reasoning leads us

\footnotetext{
${ }^{20}$ This distinction seems in many ways analogous to the distinction between two "varieties of grounding" to be found in Turner 2017.

${ }^{21}$ Note that negative existential truths according to the sparse view are, as it were, doubly disjunctive: on the one hand, the totality which exhausts the ground might occur in different ways within a possible world - a fact the second objection explored - and, on the other hand, they have distinct grounds across possible worlds. The latter kind of disjunctivity, which is a characteristic of the sparse and the abundant view alike, is at stake in the third objection. Thanks to an anonymous referee for suggesting me to be more explicit about this.
} 
to suppose that there are many ways in which Vulcan, to stay with our example, could not have existed.

This concludes the objections against the proposed accounts. To wrap up what was said thus far: the abundant view generates partial grounding claims which go against the relevance constraint on grounding. The sparse view, while faring a bit better on this front, has strange consequences when conjoined with the Internality principle. Moreover, both accounts seem to press us to accept that there are numerous ways in which negative existential claims can hold, which might upon reflection be put to doubt. Can one do any better? In the following, I will outline a new proposal which arguably motivates a positive answer to this question.

\section{The Ground of All Negative Existential Truths}

As standardly regimented, sentences expressing grounding explanations are at most many-one. Thus a truth might hold because a plurality of truths holds, as in the usual cases of the grounds of conjunctions and universal generalizations. Recently, Dasgupta (2014) challenged this regimentation. According to him, there are tenable views in metaphysics whose adequate formulations call for the acceptance of grounding claims in which the role of groundee is also played by a plurality of truths. Even though a full presentation of these views is beyond the scope of this paper, it will be handy to have two of these views available for illustration.

Comparativism about Mass (henceforth Comparativism) is the view according to which attributions of mass values to objects - e.g. that Dasgupta's laptop has $2 \mathrm{~kg}$ mass - are grounded in the holding of relations between the masses of the laptop and other objects in general. In turn, Qualitativism is the view of those who hold that non-qualitative, or individualistic truths, that is truths only expressible by means of sentences mentioning particular individuals - e.g. that Dasgupta is a philosopher - are grounded in wholly qualitative truths, that is truths expressible by means of sentences not referring to any object in particular - e.g. that someone is a philosopher. $^{22}$

To help appreciate Dasgupta's point, consider Qualitativism. Take the truth that Obama exists, which is a non-qualitative truth. What could be its ground, according to the view? Dasgupta argues that, if Necessitarianism is accepted, any alleged qualitative ground which

${ }^{22}$ Litland (2016) suggests that a version of mathematical structuralism should be cashed out in many-many grounding terms. 
necessitates Obama's existence will be guilt of irrelevance. For the most plausible candidate would be the plurality of every qualitative truth plus the totality truth that these are all. But this ground obtains partially due to qualitative truths concerning, e.g. Alpha Centauri, me, you and each other object in the universe. Since these truths are irrelevant to the existence of Obama, the view as it stands should be rejected (Dasgupta 2014, pp. 8ff.).

Similar problems haunt Comparativism. For example, that Dasgupta's laptop has $2 \mathrm{~kg}$ is grounded in mass relations it has to other objects. On pain of irrelevance, that the laptop is two times the mass of a particular stone in the Elbe river has no bearing on making it the case that the laptop satisfies the mass attribution (Dasgupta 2014, p. 16).

Dasgupta then argues that if we allow that grounding claims be many-many, i.e. that not only pluralities might ground truths, but pluralities might be grounded as such, these views do not fall prey to the objections he raises. Thus, according to the revised version of Qualitativism, all non-qualitative truths taken together are grounded in all qualitative truths taken together. Similarly, Comparativism in its revised version would then underwrite a different claim, namely that the mass attributions, taken together, obtain because the statements of mass relations between the objects, taken together, obtain. Since the fix to the formulations of these tenable views employs a many-many "because" operator, the correct regimentation of grounding claims should not be restricted to one-many cases, as the usual account has it, but must make room for claims of the form $\ulcorner\Gamma$ because $\Delta^{\urcorner}$, for $\Delta, \quad \Gamma$ pluralities of sentences. ${ }^{23}$

Dasgupta's point has far-reaching consequences to how we should treat questions of fundamentality. For it gestures to the possibility that a truth be explainable only qua member of a plurality of truths. And if the irreducibly plural cases raised are tenable, we seem pressed to conceive of different notions of fundamentality, of distinct strengths, corresponding to the availability of explanations considering the truth in question singularly or as included in a plurality of further truths. A fundamental truth in the strongest sense would then be a truth for which no (full) metaphysical explanation

${ }^{23}$ It bears mentioning that the cases presented by Dasgupta are irreducibly plural in the sense that the many-many claims suggested by the accounts are not equivalent to many-many claims definable by means of a one-many grounding operator and the usual connectives. Interestingly, Bolzano (1837) adopts a many-many regimentation. It is clear from his text, however, that he does not allow for irreducibly plural cases as the ones Dasgupta presents. 
can be given; and such that no plurality of truths to which the truth in question belongs can be (fully) metaphysically explained. ${ }^{24}$ If this notion of fundamentality is accepted, metaphysicians striving to make their case for the non-fundamentality of some class of truths - such as mass attributions and non-qualitative truths - have a further dialectical route to pursue, namely, to indicate a metaphysical (full) explanation of a plurality of truths including the truths in the class under consideration.

Taking Dasgupta's suggestion on board, we are now in a position to consider the view that the all-embracing totality fact is the metaphysical ground for all true negative existentials, taken collectively. Regarding our working example, the account would then provide us with the following claims:

1*. Vulcan does not exist, Sherlock Holmes does not exist, Santa Claus does not exist,... because (I exist, you exist, this pen exists, $\ldots, \forall x((x=m e) \vee(x=y$ ou $) \vee(x=$ this pen $) \vee \ldots))$

2*. Vulcan does not exist, Sherlock Holmes does not exist, Santa Claus does not exist, ... because $\forall x((x=m e) \vee(x=y o u) \vee(x=$ this pen) $\vee \ldots)$ )

I will label the proposal underwriting $1^{*}$ the revised abundant view, and the one underwriting $2^{*}$ the revised sparse view. In the following, I will argue that these revised views bypass the objections previously raised. For ease of exposition, I will consider these in reverse order. ${ }^{25}$

Let us start by considering the worry that the content of negative existentials do not, in general, suggest that there are many ways in

${ }^{24}$ In symbols:

$\mathrm{p}$ is a fundamental ${ }^{*}$ truth $\leftrightarrow_{d f} \mathrm{p} \wedge \neg \exists \Delta$ (p because full $\left.\Delta\right) \wedge \neg \exists \Gamma \exists \Theta((\mathrm{p}$ is among $\Gamma) \wedge\left(\Gamma\right.$ because $\left.\left._{\text {full }} \Theta\right)\right)$.

Where "is a fundamental* truth" is meant to be here a unary sentential operator. Since a single truth is a plurality in our sense, the second conjunct is superfluous. Since it expresses, however, the usual conception of fundamentality cashed out in one-many grounding terms, it is added here for expository purposes.

${ }^{25}$ Since plausibly our capacity of effectively naming nonexistents falls short of covering all of them, it might well be the case that the list aimed at in these accounts is not strictly speaking statable in our languages. Cf. the discussion in the introductory section. I assume we have the means of simulating this list, i.e. stating the plurality of all negative existential truths, via quantification over merely possible objects, or substitutional quantification over sentences in possible languages, or higher order quantification directly over possible truths, or the like. A full discussion of this point is beyond the scope of this paper. 
which they might hold. On either of the revised accounts, we need to consider the groundee as the plurality of all true negative existential truths. Now since every possible object is virtually either referred to in the groundee or the ground - that is, in the plurality of negative existentials or the totality truth which grounds them - the accounts predict that the plurality of negative existential truths has only one way for it to obtain. For, according to these accounts, the list of every nonexisting object cannot be altered unless the totality truth itself, i.e. the ground, be changed along with it. Thus both the revised abundant and the revised sparse views do not assign multiple ways for the plurality of negative existential truths to hold.

At this point, note that the accounts are silent as far as the grounds of negative existentials go, taken singularly. And maybe there is a reasonable sense in which one might require that the accounts take some stance on this score. For our purposes, the important point, however, is that neither of them is committed to treating negative existentials, on account of their grounds, as open to multiple ways in which they might obtain. As long as negative existentials can only be explained collectively, as a 'bunch' so to speak, the revised accounts assign only one way for them to be the case, and this suffices to respond to the objection we are considering.

A related line of reasoning shows that the second objection, pertaining only to the sparse view, does not get off the ground when applied to the corresponding revised version. For each plurality of negative existentials has only one ground across possible scenarios. In order to state the tension with Internality, I relied on a possible expanded ground of the same groundee on which the objection depended. But no such expansion is now possible: grounds of negative existentials and the distinct pluralities of these correspond one-one, in light of the revised accounts. Thus the second objection also cannot be raised in this case.

As it concerns the irrelevance objection with which we started, matters are less clear. To recall, the objection states that the accounts, together with plausible assumptions on the logic of grounding, entail such strange claims as that you and me existing partially grounds that Vulcan does not exist. For the totality truth that you, me and every existent object exists and that we are all there exists obtains partially because you and me exist. What we have here seems to be a failure of the following relevance constraint: if $p$ because $\Delta$, then for every $q$ in $\Delta, q$ is relevant to $p .^{26}$

${ }^{26}$ For simplicity, I employ "is relevant to" as an operator, applicable to sentences 
Now the same objection, if directed against the revised accounts, depends on the specific form the relevance constraint takes when extended to cover irreducibly plural cases. If, for example, it states that whenever $\Gamma$ because $\Delta$, then for every $p$ in $\Delta$ and every $q$ in $\Gamma, p$ is relevant to $q$, then the objection still goes through. For since in the cases we are considering negative existentials are all gathered together in the plurality instantiating " $\Delta$ " - i.e. each one of them would instantiate " $p$ " in the foregoing constraint-, we would be confronted with the same failure of relevance encountered before.

However, it is clear that the relevance constraint thus stated is too strong if we make room for irreducibly plural cases. Take Qualitativism. Obviously, this view does not obey the proposed version of the relevance constraint. For among the qualitative truths there will be plenty of truths wholly irrelevant, for example, to Obama's existence, which is among the non-qualitative ones in the groundee. Thus the relevance constraint, as stated, should be rejected, since it would rule out irreducibly plural grounding cases which motivated our move to many-many grounding claims in the first place.

A much more promising extension of the relevance constraint is the following. If $\Gamma$ because $\Delta$, then for every $p$ in $\Delta$, there is a $q$ in $\Gamma$, such that $p$ is relevant to $q$; and for every $q$ in $\Gamma$, there is a $p$ in $\Delta$, such that $p$ is relevant to $q$. Since relevance is "distributed" over the pluralities one by one, one could reasonably regard this constraint as a statement of a certain distributive notion of relevance between the pluralities standing as ground and groundee. In the following, I will label this the distributive relevance constraint.

Whether the cases raised by Dasgupta obey this latter version of the relevance constraint is hard to decide. Crucially, if the latter constraint is taken for granted, then it seems the revised accounts we are considering still fall prey to the relevance worry raised at the beginning. For the totality truth is not relevant to each of the negative existentials in the plurality it grounds, as the constraint, stated in this form, would predict. It seems to me, however, that there are independent motivations for rejecting this distributive form of the constraint.

Firstly, though Dasgupta is not committal to any specific formulation of Qualitativism, surely something in the lines of the following should be an eligible candidate:

and pluralities of them. I assume this operator is symmetric in the straightforward way. Cf. Schlesinger 1986. 
Obama exists, Dasgupta exists, Dasgupta is a philosopher, ... because $\exists x_{1}\left(O x_{1}\right), \exists x_{2}\left(\mathrm{D} x_{2}\right), \ldots, \forall x(O x \vee D x \vee \ldots)$

(Where "O" is a complex predicate specifying the intrinsic nature of Obama, "D" is a predicate specifying the intrinsic nature of Dasgupta, and so on for every individual cited in an individualistic truth on the left-hand side of "because".) The idea is clear: all the individualistic truths obtain because there is an object satisfying the intrinsic nature corresponding to each of the individuals, together with the truth that they are all. ${ }^{27}$ Arguably, this formulation of Qualitativism does not obey the distributive relevance constraint. For the qualitative totality truth -i.e. that expressed by " $\forall x(O x \vee D x \vee \ldots)$ " above - is not relevant to any particular individualistic truth included in the groundee. (Indeed, that this is the case is an essential part of the motivation for the qualitativist to go many-many in the first place.) Thus there is a truth in the plurality standing as ground which no particular truth in the plurality standing as groundee is relevant to, contrary to the relevance constraint just stated. ${ }^{28}$

Secondly, the consideration of concrete cases seems to suggest that we should allow for an irreducible notion of relevance between pluralities. Thus assume the distributive relevance constraint is true. Now if we allow transitivity in the many-one case, we should extend it to many-many cases. That is, the following should hold for manymany grounding: ${ }^{29}$

$\forall \Delta \forall \Theta \forall \Gamma(((\Theta$ because $\Delta) \wedge(\Gamma$ because $\Theta)) \rightarrow(\Gamma$ because $\Delta))$

Consider Comparativism. Accordingly, the truth that Dasgupta's laptop has $2 \mathrm{~kg}$ mass is among the plurality of all the true claims attributing a mass value to some object. This plurality obtains because Dasgupta's laptop is twice as heavy as a stone in the Elbe, a third of what a particular 6 kilograms pumpkin weighs, and so on. Now suppose one endorses the view that these latter claims of proportion are

${ }^{27}$ Dasgupta's discussion is strongly suggestive of this formulation in 2014, pp. $10 \mathrm{ff}$.

${ }^{28}$ Note that a natural fix would be to quantify over pluralities in stating the distributive form of the relevance constraint. However, even granting that the totality truth is relevant to the plurality of non-qualitative truths as a whole, this move would only be effective if we allow for non-distributive, irreducible relevance claims, which is the main point of discussion.

${ }^{29}$ Dasgupta formulates a Cut Rule for many-many grounding, from which Transitivity is derivable, but does not assume it in the course of the paper. See Dasgupta 2014, p. 5. 
plurally grounded in relations between sets. By the transitivity principle just formulated, the mass attributions are then plurally grounded in relations between sets. But, plausibly, the distributive relevance constraint cannot apply here: it is not the case that each relational truth about sets is relevant to a mass attribution to the particular objects. While one could perhaps motivate the claim that a truth about a set is relevant to a mass attribution concerning the members of it, many of the former truths will relate pure sets, sets of sets, and so on, thus sets to whose members no mass can be attributed at all. If the conjunction of those grounding claims constitutes a tenable position - as it surely seems to- we thus have a further reason to reject the distributive version of the relevance constraint.

In light of these two considerations, it seems that the most plausible extension of the constraint on relevance to many-many grounding claims, and the one which most fairly respects the irreducibly plural cases, also takes relevance to hold irreducibly between the pluralities themselves. Accordingly, if $\Gamma$ because $\Delta$, then $\Delta$ is relevant to $\Gamma$, even if, were the truths therein taken separately, relevance is not "distributed" between these pluralities. Importantly, given the definition of partial grounds, this means that, at least in some irreducibly plural cases, partial grounds need not be (individually) relevant to their groundees.

If the foregoing is right, then the reasoning which would lead to the irrelevance objection in the revised versions is neutralized. For, by making room for irreducibly plural cases, we no longer require that the partial grounds be relevant to the true negative existentials taken together, let alone to each of them taken separately from this plurality.

Admittedly, this still leaves open the question as to whether the totality truth, on either of the revised accounts, is indeed (irreducibly) relevant to the plurality of negative existentials. In addressing this issue, let us note that one of the main difficulties regarding the whole issue of the grounds of negative existentials is that the objects which do not exist cannot take part, as it were, in such grounds. Thus both the original and revised accounts point to objects in the ground distinct from the objects mentioned in the groundee. However, by considering all the nonexistents as a whole in the revised accounts, we deliberately lose track of the particularities of the objects involved which seem to lie at the heart of the charge of irrelevance. In other words, the totality truth does not 'aim at' Vulcan, Sherlock Holmes, or any particular nonexistent whatsoever, but rules their existence 
out indiscriminately. In addition, to mention a closely related point, it should also be recognized that the revised views have something going for them insofar as it seems acceptable that the existents, on account of their existence, are relevant to all the nonexistents, on account of their nonexistence, regardless of the particulars on either side of the grounding claim. Even though a decision on this issue has to await for particular renderings of the notion of relevance at play, it seems clear that the prospects of the revised accounts look more promising when weighed against their unrevised versions we started with.

Summing up, the revised accounts score better than the original accounts when it comes to the objections considered: the revised accounts do not suggest, in themselves, that there are multiple ways in which negative existential truths obtain, since accordingly we need consider only their obtaining as a plurality; on either of the revised proposals, no object, existent or not, is left out of consideration in the resulting claim - it is "mentioned" on one of the sides of the grounding claim-, thus the conflict with Internality does not arise; finally, there is a case to be made in favor of a notion of relevance which applies irreducibly between pluralities of truths in irreducible many-many grounding explanations, in view of which the charge of irrelevance cannot apply.

Let me add a final point on the appraisal of the proposals just examined. The underlying picture of the grounding relation between existents and nonexistents seems an elegant one in light of the revised accounts. To put it pictorially, the totality truths cut reality in two halves: the half of the existent, and the half of the nonexistent. Again, the truth that these are all the existents does not take into account any particularity of the entities it rules out: it makes the others not exist "in one stroke". In analogy with the cases of Qualitativism and Comparativism, we should then say that all the nonexistents do not exist because all the existents exist (and they are all), even if one cannot derive from this any metaphysical explanation of the negative existential claims taken separately from this plurality.

\section{Conclusion}

Some explanatory theses in metaphysics — notably Comparativism about mass attributions, Qualitativism, probably further theses of a similar structuralist spirit- arguably press us to make room for irreducibly many-many grounding statements to account for what is more fundamental than what. In this paper, I argued that the natural 
view according to which negative existential truths are grounded in the totality truth citing every existent should be added to this list. ${ }^{30}$

\section{REFERENCES}

Armstrong, D., 1997, A World of States of Affairs, Cambridge University Press, Cambridge. (doi:10.1017/CBO9780511583308)

Bliss, R. and K. Trogdon, 2016, "Metaphysical Grounding", The Stanford Encyclopedia of Philosophy, Edward N. Zalta (ed.), <https://plato.stanford.edu/archives/win2016/entries/grounding/>.

Bolzano, B., 1837/2014, Theory of Science, translated by R. George and P. Rusnock, Oxford University Press, Oxford.

Correia, F. and B. Schnieder (comps.), 2012, Metaphysical Grounding: Understanding the Structure of Reality, Cambridge University Press, Cambridge.

— , 2012a, "Grounding: An Opinionated Introduction", in F. Correia and B. Schnieder 2012, pp. 1-36.

Dasgupta, S., 2014, "On the Plurality of Grounds", Philosophers' Imprint, vol. 14, no. 20, pp. 1-28.

Evans, G., 1979, "Reference and Contingency", The Monist, vol. 62, no. 2, pp. 178-213.

Fine, K., 2012, "Guide to Ground", in F. Correia and B. Schnieder 2012, pp. 37-80.

Hale, B. and A. Hoffmann (comps.), 2010, Modality: Metaphysics, Logic, and Epistemology, Oxford University Press, Oxford.

Leuenberger, S., 2014, "Total Logic", Review of Symbolic Logic, vol. 7, no. 3. pp. 529-547. (doi:10.1017/S1755020314000124)

Litland, J., 2016, "Pure Logic of Many-Many Ground", Journal of Philosophical Logic, vol. 45, no. 5, pp. 531-577. (doi: 10.1007/s10992-0159386-2)

— , 2015, "Grounding, Explanation, and the Limit of Internality", Philosophical Review, vol. 124, no. 4, pp. 481-532. (doi:10.1215/003181 08-3147011)

Loss, R., 2017, "Grounding, Contingency and Transitivity", Ratio, vol. 30, no. 1, pp. 1-14. (doi: 10.1111/rati.12109)

Lovett, A., 2019, "A Simple Proof of Grounding Internality", Thought: A Journal of Philosophy. (doi:10.1002/tht3.416)

Merricks, T., 2007, Truth and Ontology, Oxford University Press, Oxford.

\footnotetext{
${ }^{30}$ For reading and commenting on earlier versions and material from which the paper originated, I thank Roberto Loss, Stephan Kram̈er, Benjamin Schnieder and members of the Doktoranden Kolloquium in Hamburg. While working on this paper I was funded by the Coordination for the Improvement of Higher Education Personnel (CAPES) from Brazil.
} 
Moore, G.E., 1936, “Is Existence a Predicate?”, Aristotelian Society Supplementary Volume, vol. 15, no. 1, pp. 175-188.

Rosen, G., 2010, "Metaphysical Dependence: Grounding and Reduction", in B. Hale and A. Hoffmann 2010, pp. 109-136.

Schlesinger, G., 1986, "Relevance", Theoria, vol. 52, no. 1-2, pp. 57-67.

Turner, J., 2017, "Curbing Enthusiasm About Grounding", Philosophical Perspectives, vol. 30, no. 1. pp. 366-396. (doi: 10.1111/phpe.12087)

Williamson, T., 1999, "Existence and Contingency", Proceedings of the Aristotelian Society, vol. 73, no. 1, pp. 181-203. (doi: 10.1111/14678349.00053)

Received: June 4, 2019; revised: October 21, 2019; accepted: December 28, 2019. 